\title{
INVESTIGATING THE USE OF 3D GEOVISUALIZATIONS FOR URBAN DESIGN IN INFORMAL SETTLEMENT UPGRADING IN SOUTH AFRICA
}

\author{
Victoria Rautenbach ${ }^{\mathrm{a}},{ }^{*}$, Serena Coetzee ${ }^{\mathrm{a}}$, A. Çöltekin ${ }^{\mathrm{b}}$ \\ ${ }^{a}$ Centre for Geoinformation Science, Department of Geography, Geoinformatics and Meteorology, University of Pretoria, Pretoria, \\ South Africa, victoria.rautenbach@up.ac.za, serena.coetzee@up.ac.za \\ ${ }^{\mathrm{b}}$ GIScience Center, Department of Geography, University of Zurich, CH-8057, Zurich, Switzerland - arzu@geo.uzh.ch
}

Commission II, WG II/6

KEY WORDS: urban design, map reading, geovisualization, 3D, informal settlements, South Africa

\begin{abstract}
:
Informal settlements are a common occurrence in South Africa, and to improve in-situ circumstances of communities living in informal settlements, upgrades and urban design processes are necessary. Spatial data and maps are essential throughout these processes to understand the current environment, plan new developments, and communicate the planned developments. All stakeholders need to understand maps to actively participate in the process. However, previous research demonstrated that map literacy was relatively low for many planning professionals in South Africa, which might hinder effective planning. Because 3D visualizations resemble the real environment more than traditional maps, many researchers posited that they would be easier to interpret. Thus, our goal is to investigate the effectiveness of 3D geovisualizations for urban design in informal settlement upgrading in South Africa. We consider all involved processes: 3D modelling, visualization design, and cognitive processes during map reading. We found that procedural modelling is a feasible alternative to time-consuming manual modelling, and can produce high quality models. When investigating the visualization design, the visual characteristics of 3D models and relevance of a subset of visual variables for urban design activities of informal settlement upgrades were qualitatively assessed. The results of three qualitative user experiments contributed to understanding the impact of various levels of complexity in 3D city models and map literacy of future geoinformatics and planning professionals when using 2D maps and 3D models. The research results can assist planners in designing suitable 3D models that can be used throughout all phases of the process.
\end{abstract}

\section{INTRODUCTION}

Informal settlements have been described as a living organism, indivisible and always changing (Kostof, 1993). They are characterized by rapid and unstructured expansion, poorly constructed buildings, and in some cases they are on disputed land (Mason et al., 1997; Huchzermeyer and Karam, 2006). Informal settlements commonly originate on unoccupied land along the urban edge or land that might be difficult to develop, such as on steep slopes or areas prone to flooding. Kostof (1993) stated that the informal settlement upgrading process immediately starts and never truly ends. A strong sense of community can be observed in these settlements, and the inhabitants often collectively approach upgrading projects, such as constructing communal water taps. Non-profit organizations (NGOs) are also actively involved in community participation initiatives for informal settlement upgrading, through which the inhabitants are empowered and can play an active role in the development process. Another major stakeholder in the informal settlement upgrading process is the government. The two main strategies that can be followed are in-situ upgrading or relocation of the settlement.

Informal settlements are a common occurrence in the South African landscape. In response, the South African government has produced various strategies on informal settlement upgrading, such as the South African Housing Programme (Department of Human Settlements, 2009) and the National
Development Plan (National Planning Commission, 2012). Informal settlement upgrading by definition requires a strong emphasis and focus on the community. The upgrading process should therefore be flexible so that it can be adjusted to the dynamics of the existing community and potential impact of the various development options. When considering this, the Housing Development Agency (HDA) suggests that an urban design process be implemented (Housing Development Agency, 2011). As soon as the urban design project is initiated, there are several considerations: how much time is there for the project?; is there sufficient information available?; and is the required human capacity available (including skills)? (Jha et al., 2010).

Pervious research documented that planning professionals in South Africa have a low level of map literacy which can hinder effective planning (Clarke, 2007; Marais, 2007; Engel, 2004). This, worryingly, means that the principal party responsible for planning might not have the adequate skills and abilities to perform the urban design tasks associated with informal settlement upgrading. On the other hand, progress in mapping technology allows the user to display information on digital platforms, such as web maps or virtual globes - these can either eliminate some map reading limitations or introduce new challenges due to computer illiteracy. Geographical visualization (geovisualization) provides alternative methods of exploring both the information display and the data behind the information (Cartwright et al., 2005), and the impact of these new alternatives on map literacy needs to be investigated.

\footnotetext{
${ }^{*}$ Corresponding author
} 
The goal of this project is to investigate the use of alternative 3D geovisualizations for urban design of informal settlement upgrading in South Africa. In this paper, we combine results and observations from various experiments and studies to address this goal. We organize the paper based on three stages in the visualization process: the 3D modelling, visualization design, and the user's cognitive processes related to spatial tasks on 3D geovisualizations and comparable alternatives (i.e., topographic maps, aerial photographs, 2D maps) when performing basic map reading tasks for informal settlement upgrading. The remainder of the paper is structured as follows: Section 2 presents procedural modelling as an alternative to manual modelling; in Section 3 visualization design is discussed based on visual characteristics, visual complexity and visual variables; in Section 4, results from empirical user studies on the usefulness of 3D models are presented; and in Section 5, the overall results and observations are discussed and conclusions are provided.

\section{DEVELOPMENT OF 3D MODELS}

Spatial data are generated daily in unprecedented amounts and these new rich and 'big' data need to be visualised, analysed, and managed ( $\mathrm{Li}$ et al., 2016). Visual representations of spatial data proved valuable to facilitate thinking, understanding, and knowledge construction about humans and their physical environment (Hildebrandt and Döllner, 2010). One such visualization type is a 3D city model, i.e., a digital representation of spatial objects, structures and phenomena in urban areas. 3D city models have been of interest in domains related to geography for a long time, and are increasingly built and leveraged in various applications, such as urban planning and environmental management (Coltekin and Haggren, 2000; Ross, 2010; Chen et al., 2011; Krüger and Kolbe, 2012; Biljecki et al., 2015).

3D models allow users to develop and design 3D representations with various datasets, perform analysis, such as line of sight (visibility), and to create simulations (Hildebrandt and Döllner, 2009; Cartwright et al., 2005). 3D models can present information that cannot be visualised in 2D maps and designs (Li et al., 2010). However, the development of high quality realistic 3D urban models is still challenging and requires skilled individuals (Rautenbach et al., 2015a). Additionally, manual modelling can be time consuming, and involves a great deal of labour and time (Müller et al., 2006; Rautenbach et al., 2015a). Employing only manual modelling when developing 3D models for an informal settlement is not a feasible solution due to the constant changing nature of informal settlements.

Rautenbach et al. (2015a) investigated the use of procedural modelling for generating a 3D model of an informal settlement in South Africa. Procedural modelling employs algorithms to automatically generate 3D objects and construct 3D models (Ilčík et al., 2010; Müller et al., 2006). This is a suitable alternative for modelling South African informal settlements, as the majority of the settlements are composed of numerous structures of more or less the same shape and size (i.e. the dwellings in the settlement). Planners and geoinformatics professionals can utilize procedural modelling to produce highquality level of detail (LoD), specifically LoD2 3D models that can be used throughout the informal settlement upgrading process (Rautenbach et al., 2015a). Refer to Figure 1 for an example of the model that was developed. The generated model is an abstract representation of the settlement and it would be quite difficult to generate a photorealistic representation. It should be noted that procedural modelling does not overcome all the limitations of manual modelling. For example, procedural modelling still requires skilled individuals, however, the skill set is different (requires scripting). A great deal of initial planning and preparation is still required to generate models in near real-time.

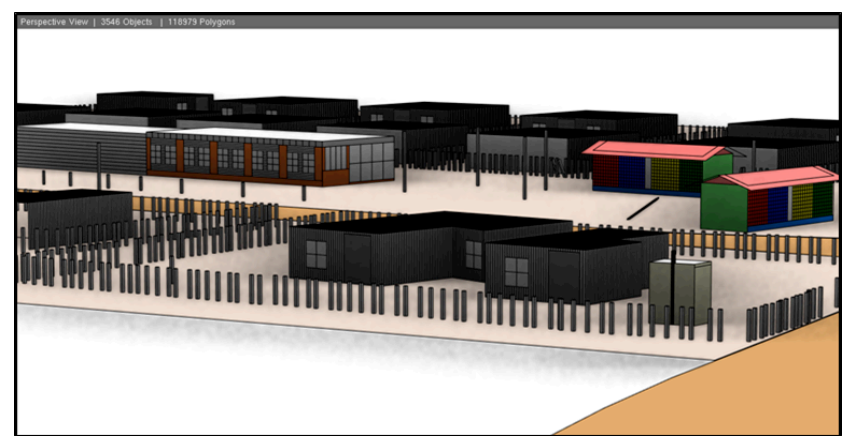

Figure 1. A section of the Slovo Park informal settlement modelled at LoD3. Source: Rautenbach et al. (2015a)

\section{VISUALIZATION DESIGN AND 3D MODELS}

Meng (2002) argues that a photorealistic 3D model is not always the most ideal for spatial perception, analysis, understanding and knowledge discovery. For some applications non-photorealistic 3D models can prove to be more effective and efficient. They are also produced at a lower cost. However, there are no guidelines about which method is more optimal for planning. Anecdotal evidence has suggested that nonphotorealistic models would be useful when capturing community knowledge, as the local community do not require much detail to recognise the environment and different objects (Rautenbach et al., 2015a). In this section, we address some of these issues by discussing the visualization design of $3 \mathrm{D}$ informal settlement models. There are numerous aspects to consider when discussing visualization design. In this research we considered visual characteristics, visual variables and visual complexity.

Dickmann and Dunker (2014) identified visual characteristics for 3D building models in urban planning. The characteristics were divided into three main aspects: visualization content, visualization application environment and functionality, and visualization performance. Rautenbach et al. (2015b) adapted these characteristics for 3D informal settlement models in urban design activities, and additionally the importance of each characteristic to stakeholders were included. The visualisation characteristics provide guidance to users on which features to focus on when developing 3D models of informal settlements. When considering urban design activities in informal settlements, Rautenbach et al. (2015b) identified the LoD, terrain model, topography, man-made structures, and movement network as major contributions for stakeholder understanding of the model. When considering which software to use for presenting the model, the ability to easily navigate and view the 3D model from various perspectives is very important to consider. Lastly, when developing any 3D model the 'costbenefit' ratio is an important consideration, as 3D modelling can be very effort and time intensive.

Visual variables are a well-known concept defined by Bertin (1983) and originally proposed for black and white hardcopy 
maps. Various researchers recommended extensions for interactive displays and animations (DiBiase et al., 1992; MacEachren, 1995; Köbben and Yaman, 1996). The relevance of a subset of the visual variables were evaluated specifically for geovisualization requirements of upgrades in informal settlements (Rautenbach et al., 2015b). To increase the selectiveness of 3D objects ${ }^{2}$, Rautenbach et al. (2015b) proposed the following visual variables as relevant: position and motion of the camera, and colour and texture, suggesting shape to be replaced with LoD as this is used generally in computer graphics to enhance or reduce the detail of an object. LoD was identified as a characteristic of a 3D informal settlement (Rautenbach et al., 2015a), and suggested as a highly relevant visual variable (Rautenbach et al., 2015b). Manipulating the LoD of an object can contribute to the saliency of the object, as a detailed 3D object (higher LoD) will be more pronounced in an environment with few detailed objects. Additionally, the deliberately designed level of detail might contribute to the stakeholders' understanding of the environment and the proposed upgrades in the informal settlement.

\section{COGNITION AND 3D MODELS}

Researchers have been debating the usefulness and effectiveness of 3D representation for various application fields, including domains related to geography (Hegarty et al., 2009; Coltekin et al., 2015a; Coltekin et al., 2015b). One school of thought is that 3D models can assist users to orientate themselves in a familiar environment and can make understanding landforms easier than with traditional 2D representations (Chen et al., 2011; Smallman et al., 2007; Wood et al., 2005; van Lammeren et al., 2010). Another school of thought posits that $3 \mathrm{D}$ representations will lead to cognitive overload, and that this might outweigh the benefits (Bleisch and Nebiker, 2008; Richards and Taylor, 2015; Métral et al., 2012).

There have been various studies exploring the feasibility of developing 3D models from existing tools (i.e. various desktop and web technologies) for urban planning (Ahmed and Sekar, 2014; B. Chen et al., 2011; Chen, 2011; Dambruch and Krämer, 2014; Fisher-Gewirtzman, 2012). These studies found that 3D models with a low LoD can be developed easily and 3D volumetric analyses would be useful in planning activities. Sharing of information and proposed future developments encouraging public participation in urban planning are also highlighted in these studies.

Virtual globes are easily accessible, and allow users to effectively create 3D visualizations of various types of spatial data (Bleisch and Nebiker, 2008; Schroth et al., 2011). However, not all these visualizations are successful which can be attributed to the lack of guidelines for creating effective representation. Schroth et al., (2011) investigated the usefulness of virtual globes as an interactive community engagement tool for landscape planning, specifically focused on 3D modelling of climate change vulnerability. After stakeholder interviews and questionnaires, Schroth et al. found that 3D models portrayed in a virtual globe were a great tool to provide access to spatial data and to raise awareness for the specific project. However, the risk of misinterpretation of the models was a barrier for use.

\footnotetext{
${ }^{2}$ A visual variable is selective if a mark can be changed in only this variable and easily differentiated afterwards (Bertin 1983; Carpendale 2003; Halik 2012; Wang et al. 2012).
}

Herbert and Chen (2014) used a survey and interviews to examine the perceived impact of 3D models on the impact on constructing mental images, shadow preferences and understanding which planning task would be useful for urban planning. Participants indicated that viewing the proposed developments in a 3D environment allowed them to construct and improve their familiarity faster than with traditional 2D maps. However, the participants also indicated that prior knowledge of the site is essential. Herbert and Chen (2014) found that the 3D models were useful for complex planning tasks, such as showdown impact), but not so effective for simple tasks, such as measurements. This was based on asking participants to rate their perceived usefulness of $3 \mathrm{D}$ for the specific task using a Likert-scale.

Rautenbach et al. $(2014 ; 2016)$ approached this question of the usefulness of 3D models for planning tasks more directly by developing a series of user experiments to assess individuals' map literacy when performing basic map reading tasks with aerial photographs, 2D maps and 3D models. In the first iteration, the preliminary results suggested that basic map reading tasks (i.e. indicating cardinal directions, relative directions, and estimation of distance) could be successfully performed on 3D non-realistic landscapes and 3D models (Rautenbach et al., 2014). However, confirming the comparative success of these observations to their alternatives requires further (controlled) experiments.

Thus, following the initial observational study, the authors developed a map reading task taxonomy for planning (Rautenbach et al., 2016). The taxonomy consisted of six levels of map reading tasks, ranging from recognising symbols to extracting knowledge. The first four levels (recognise symbology, orientate, locate, and measure or estimate) were considered the minimum for functional map literacy and thus forming the elementary units for more advanced tasks. A subset of the taxonomy was tested using a 1:50 000 topographic map of the Barberton area in South Africa with map-literate individuals as a validation mechanism (Rautenbach et al., 2016). The results suggest that the taxonomy can provide a proper reference for evaluating topographic map literacy levels.

In the final iteration, a mixed methods experiment was designed to evaluate the usefulness of $3 \mathrm{D}$ models when performing certain map reading tasks (a subset of the map reading task taxonomy for planning) in aerial photographs, 2D maps and 3D models. The experiment consisted of a controlled and distributed online survey, and four in-depth expert interviews. The survey focussed on tasks relating to identifying features and interpreting the terrain. For the controlled survey, 36 undergraduate students (seventeen males and nineteen females) ranging from 18 to 33 years old participated in the experiment. The majority of participants were Geoinformatics students $(81 \%)$, with a couple of Geography (13\%), Meteorology (3\%) and Town and Regional planning (3\%) students also participating in the experiment. The demography for the distributed experiment was very different, as 58 individuals (twenty-two males and thirty-six females) ranging from 19 to 60 years old participated in the experiment. See Figure 2 for an overview of the participant's field of occupations.

The results from both the controlled and distributed survey suggest that map reading tasks involving identification of, or differentiating between features, are challenging to perform in 3D models (refer to Figure 3 and Figure 4). Identifying or differentiating between features was challenging, as no legend was available. Additionally, both the $2 \mathrm{D}$ map and $3 \mathrm{D}$ model 
have a great deal of abstraction and it is thus difficult to differentiate between objects. As suspected, participants were more successful in performing tasks relating to interpreting the terrain because the 3D model was static and the terrain was tilted slightly. Due to the tilted, when asked to indicate the lowest point (i.e. lowest elevation) in the environment the participants not very successful as the lowest point appeared to be in a different location. Thus, camera position and perspective of 3D models appear to be important considerations.

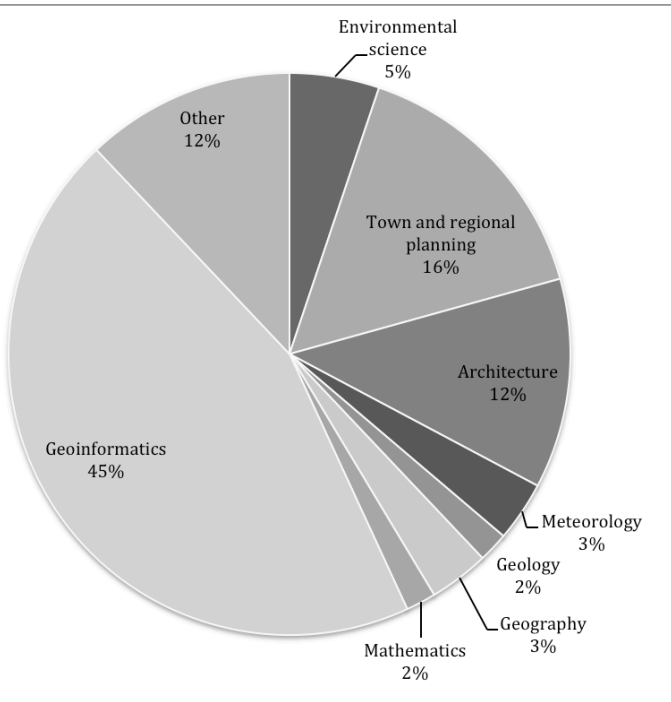

Figure 2. Overview of the participants in the distributed studies occupation

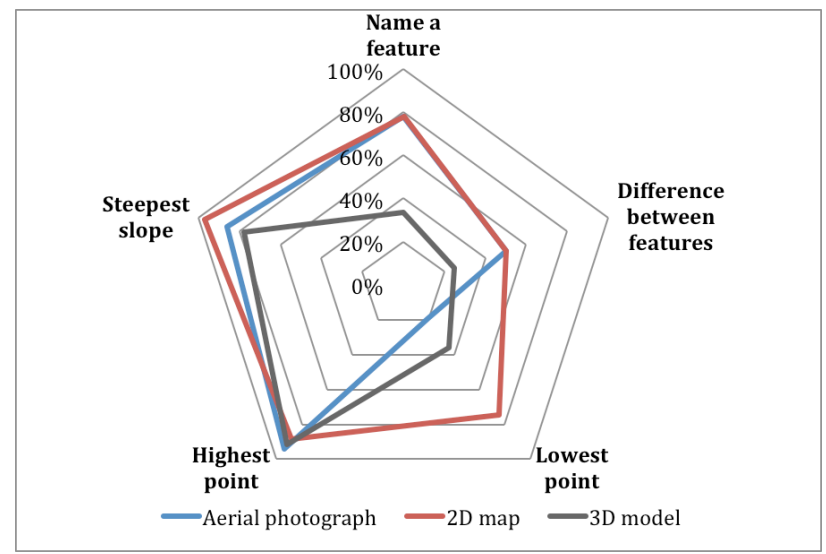

Figure 3. Radar diagram showing the percentage of correct answers for each geovisualization in the controlled experiment

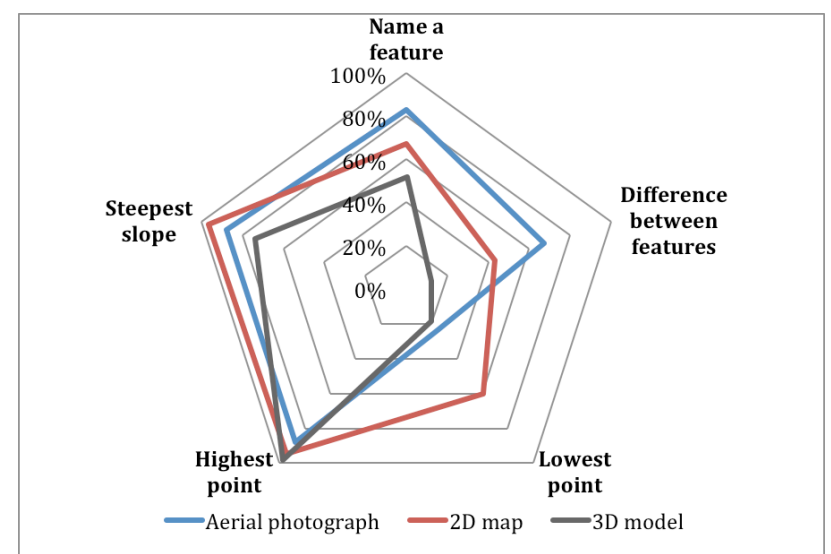

Figure 4. Radar diagram showing the percentage of correct answers for each geovisualization in the distributed experiment

In-depth interviews were conducted with four experts in planning and urban design. The main points that were raised by the interviewees were that there is definitely a place for $3 \mathrm{D}$ models in the planning process. The skills required to design and develop the 3D models are still lacking in South Africa, but recent advances in technology might overcome this. Two interviewees supported the use of 3D models for urban planning, specifically for basic analyses and supplementing site visits for locations that are remote and difficult to visit. One interviewee specified that a lower LoD is preferred as too much detail for especially a larger scale project would be costly to produce and would be overwhelming. The general consensus amongst the interviewees was that a 3D model is a useful tool to use when consulting stakeholders to gain support and to assist with their understanding of environment.

\section{DISCUSSION AND CONCLUSION}

In this paper, we present observations and results from various studies on the use of $3 \mathrm{D}$ geovisualizations for urban design in informal settlement upgrading in South Africa. The focus of the studies was on the development and visual design of 3D models, and cognition related to spatial tasks on 3D geovisualizations when performing basic map reading tasks. To combine the results presented and draw some final conclusion on the usefulness of 3D geovisualization for the urban design of informal settlement upgrades, we will use the urban design processes and guide the discussion around these processes.

Simply stated, design is the process of creating various solutions before implementation. It has also been defined as 'a complex process of gathering and combining diverse data and information into a coherent solution' (Parsaee et al., 2015). This process was then simplified by the authors further to see urban design as an iterative process that involves: understanding the current environment, designing new developments, and communicating the planned. Figure 5 presents an adaption of the conceptual model of the design process as defined by Parsaee et al. (2015).

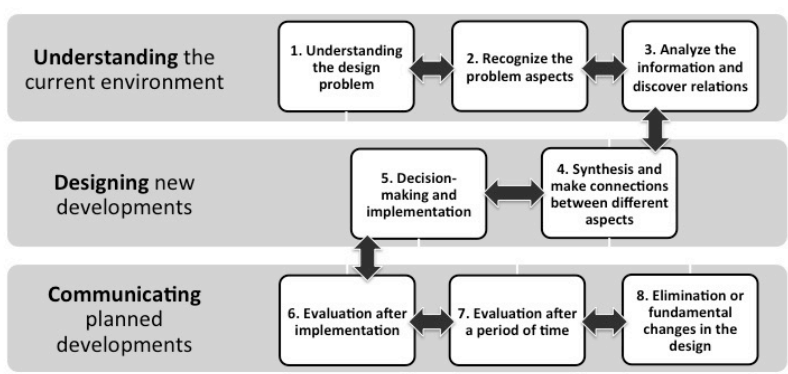

Figure 5. Conceptual design process from Parsaee et al. (2015) adapted by the authors

Before the 3D model can be used in the urban design process, it first needs to be developed. A 3D model of an informal settlement can be developed using modelling software, LiDAR or photogrammetry. LiDAR and photogrammetric tools are expensive technology, and while they may be available for urban centres, they are rarely available for informal settlements. Thus, 3D models are often created using manual modelling software, such as Trimble's SketchUp or Autodesk's Revit. We 
found procedural modelling (e.g. Esri CityEngine) a feasible alternative to time consuming manual modeling. To evaluate the usefulness of procedural modelling, a 3D model was generated. All the visual characteristics of an informal settlement could be generated using procedural modelling, however, the learning curve with it might be steeper compared to manual modelling.

Whether in $2 \mathrm{D}$ or $3 \mathrm{D}$, whether as graphic design or cartography, a successful visualization design can contribute to the understanding of the represented phenomena, and can ensure that the intended message is conveyed. Visual variables provide fundamental elements to use for improving the selectiveness of objects in the model. For example, the position of the camera is important, as it can be set to focus on the planned development in a settlement. Similarly, an object with a higher LoD is a good candidate for guiding attention as it might stand out from other objects. Thus, even though visual variables were originally proposed for black and white paper maps, with some alterations they can be useful to improve selectiveness in $3 \mathrm{D}$ colour geovisualizations. Another design aspect that should be considered is visual complexity. Complex visualization environments can lead to cognitive overload for the users, and would render a model inadequate.

Most urban design projects start with a visit to the site, to become familiar with the environment and gain insight into the community's needs. However, site visits are often not possible due to a site being located remotely or being difficult to reach. A well-designed 3D model can supplement site visits by allowing planners to view the environment from their offices at any time. Expert interviews confirmed that 3D models can be very useful to complement site visits, however, they cannot replace them.

When using 3D models to plan a new development in an informal settlement, user experiments and expert interviews suggested that currently they are most relevant to understanding and interpreting the terrain. Three user experiments were designed and implemented to assess individuals' map literacy when performing basic map reading tasks with aerial photographs, 2D maps and 3D models. The results suggested that the participants struggle to perform tasks such as identifying or differentiating between features in the LoD2 model. However, the participants were more successful when performing the tasks relating to terrain interpretation. It should, however, be noted that it is difficult to compare $2 \mathrm{D}$ to $3 \mathrm{D}$, as the level of abstraction is different and evidently the dimensions. It has been said that comparing $2 \mathrm{D}$ to $3 \mathrm{D}$ is like comparing apple to pears. Nevertheless, the results from the experiments provided an indication to what can be expected when using $3 \mathrm{D}$ models for urban planning map reading tasks.

During the interviews, the experts mentioned that more advanced analyses capabilities would be useful, however, the software is not easy to use. Additionally, modifying the 3D model to include new objects or to remove objects in real-time is not a simple task in most software applications. Currently, the development of 3D models is outsourced in most cases.

The communication phase of the urban design process is where the strength of 3D models lies. During the expert interviews, all interviewees stated that currently $3 \mathrm{D}$ models would be used to communicate the planned developments to the various stakeholders, from the community to government officials. Portraying the planned development as a 3D model enables the stakeholders to get a clearer picture of how the planned developments would affect themselves and the environment. Thus, increasing stakeholder buy-in for planned developments.

To conclude, 3D models can definitely be used in the urban design process of informal settlement upgrading. It should be noted that innovations for 3D modelling and viewing software are still necessary to improve the usefulness of 3D models for urban design. In future work, the requirements for 3D software will be specified. These requirements should take into consideration the technical expertise of the intended users, and the analyses and viewing capabilities that might be required during the urban design process.

\section{REFERENCES}

Ahmed, Faiz., Sekar, S.P., 2014. Using Three-Dimensional Volumetric Analysis in Everyday Urban Planning Processes. Applied Spatial Analysis and Policy. doi:10.1007/s12061-0149122-2.

Bertin, J., 1983. Semiology of Graphics: Diagrams, Networks, Maps. 1st ed. California, USA: ESRI Press.

Biljecki, Filip., Stoter, Jantien., Ledoux, Hugo., Zlatanova, Sisi., Çöltekin, Arzu., 2015. Applications of 3D City Models: State of the Art Review. ISPRS International Journal of GeoInformation 4 (4): pp. 2842-2889.

Bleisch, S., Nebiker, S., 2008. Connected 2D and 3D Visualizations for the Interactive Exploration of Spatial Information. In The International Archives of the Photogrammetry, Remote Sensing and Spatial Information Sciences, pp. 1037-1042. Beijing, China.

Cartwright, W., Pettit, C., Nelson, A., Berry, M., 2005. Community Collaborative Decision-Making Tools: Determining the Extent of 'Geographical Dirtiness' for Effective Displays. In 21th International Cartographic Conference.

Chen, B., Huang, F., Fang, Y., 2011. Integrating Virtual Environment and GIS for 3D Virtual City Development and Urban Planning. In 2011 IEEE International Geoscience and Remote Sensing Symposium, pp. 4200-4203. IEEE.

Chen, R., 2011. The Development of 3D City Model and Its Applications in Urban Planning. In 2011 19th International Conference on Geoinformatics, pp. 1-5. IEEE.

Clarke, DG., 2007. Impact of Map Literacy on Development Planning in South Africa. University of Stellenbosch, South Africa.

Coltekin, A., Haggren, H., 2000. VRML as a Tool for a WebBased, 3D, Photo-Realistic GIS. Proceedings of the ISPRS2000, July 14-21 33 (B5/1; PART 5): pp. 143-148.

Coltekin, A., Lokka, I., Boer, A., 2015a. The Utilization of Publicly Available Map Types by Non-Experts -- A Choice Experiment. In Proceedings of the 27th International Cartographic Conference (ICC2015).

Coltekin, A., Pettit, C., Wu, B., 2015b. Geovisual Analytics: Human Factors. International Journal of Digital Earth (8): pp. 595-598. 
Dambruch, J., Krämer, M., 2014. Leveraging Public Participation in Urban Planning with 3D Web Technology. In Proceedings of the Nineteenth International ACM Conference on 3D Web Technologies - Web3D '14, pp. 117-124. New York, New York, USA: ACM Press.

Department of Human Settlements, 2009. The National Housing Code: Part 3 Upgrading Informal Settlement. Vol. 4. South Africa.

DiBiase, D., MacEachren, A.M., Krygier, J., Reeves, C., 1992. Animation and the Role of Map Design in Scientific Visualization. Cartography and Geographic Information Science 19 (4): pp. 201-214.

Dickmann, F., Dunker, S., 2014. Visualisierung von 3DGebäudemodellen - Welche Ansprüche Stellt Die Planung an Dreidimensionale Stadtansichten? (English: Digital 3D Building Models - Which Demands Have Planners?). Kartographische Nachrichten - Journal of Cartography and Geographic Information 1: pp. 10-16.

Engel, BP., 2004. Developing Map Use Skills for Planners and Implementers of Land Reform in South Africa. GeoJournal 60: pp. $183-189$.

Fisher-Gewirtzman, D., 2012. 3D Models as a Platform for Urban Analysis and Studies on Human Perception of Space. In Usage, Usability, and Utility of $3 D$ City Models - European COST Action TU0801, edited by T. Leduc, G. Moreau, and R. Billen, 01001:01001. Les Ulis, France: EDP Sciences.

Hegarty, M., Smallman, H., Stull, A., Canham, M., 2009. Naïve Cartography: How Intuitions about Display Configuration Can Hurt Performance. Cartographica: The International Journal for Geographic Information and Geovisualization 44 (3): pp. 171-186.

Herbert, G., Chen, X., 2014. A Comparison of Usefulness of 2D and 3D Representations of Urban Planning. Cartography and Geographic Information Science 42 (1): pp. 22-32.

Hildebrandt, D., Döllner, J., 2009. Implementing 3D Geovisualization in Spatial Data Infrastructures: The Pros and Cons of 3D Portrayal Services. Geoinformatik 2009 35: pp. 1-9.

Housing Development Agency, 2011. Urban Design Framework Plan to Inform the Development and Upgrading of Informal Settlements [Draft]. South Africa.

Huchzermeyer, M., Karam, A., 2006. Informal Settlements: A Perpetual Challenge? Juta and Company Ltd.

Ilčík, M., Fiedler, S., Purgathofer, W., Wimmer, M., 2010. Procedural Skeletons. In Proceedings of the 26th Spring Conference on Computer Graphics - SCCG '10, 1:157. New York, USA: ACM Press.

Jha, A., Barenstein, J.D., Phelps, P., Pittet, D., Sena, S., 2010. Planning Reconstruction." In Safer Homes, Stronger Communities. The World Bank.

Köbben, B., Yaman, M., 1996. Evaluating Dynamic Visual Variables. In Proceedings of the Seminar on Teaching Animated Cartography, edited by FJ Ormeling, B Köbben, and R Perez Gomez, pp. 45-51. Utrecht, The Netherlands: International Cartographic Association.
Kostof, S., 1993. The City Shaped: Urban Patterns and Meanings Through History. Bulfinch.

Krüger, T., Kolbe, B., 2012. Building Analysis for Urban Energy Planning Using Key Indicators on Virtual 3D City Models - the Energy Atlas of Berlin. International Archives of the Photogrammetry, Remote Sensing and Spatial Information Sciences, Volume XXXIX-B2, 2012 XXII ISPRS Congress, 25 August - 01 September 2012, Melbourne, Australia

Li, S., Dragicevic, S., Castro, F., Sester, M., Winter, S., Coltekin, A., Pettit, C., Jiang, B., Haworth, J., Stein, A., Cheng, T., 2016. Geospatial Big Data Handling Theory and Methods: A Review and Research Challenges. ISPRS Journal of Photogrammetry and Remote Sensing 115: pp. 119-133.

Li, X., Çöltekin, A., Kraak, M., 2010. Visual Exploration of Eye Movement Data Using the Space-Time-Cube. In Geographic Information Science, pp. 295-309.

MacEachren, A.M., 1995. How Maps Work: Representation, Visualization and Design. Guilford Press.

Marais, H., 2007. The Status Quo of GIS in Municipal Town Planning Departments in Gauteng and in the Education of Town Planners. University of Johannesburg.

Mason, S., Baltsavias, E., Bishop, I., 1997. Spatial Decision Support Systems for the Management of Informal Settlements. Computers, Environment and Urban Systems 21 (3-4): pp. 189208.

Meng, L., 2002. How Can 3D Geovisualization Please Users Eyes Better? Geoinformatics Magazine for Geo-IT Professionals.

Métral, C., Ghoula, N., Falquet, G., 2012. An Ontology of 3D Visualization Techniques for Enriched 3D City Models. In Usage, Usability, and Utility of $3 D$ City Models - European COST Action TU0801, edited by T. Leduc, G. Moreau, and R. Billen.

Müller, P., Wonka, P., Haegler, S., Ulmer, A., van Gool, L., 2006. Procedural Modeling of Buildings. ACM Transactions on Graphics 25 (3).

National Planning Commission, 2012. National Development Plan 2030 Our Future-Make It Work. South Africa.

Parsaee, M., Motealleh, P., Parva, M., 2015. Interactive Architectural Approach (interactive Architecture): An Effective and Adaptive Process for Architectural Design. Housing and Building National Research Center Journal.

Rautenbach, V., Bevis, Y., Coetzee, S., Combrinck, C., 2015a. Evaluating Procedural Modelling for 3D Models of Informal Settlements in Urban Design Activities. South African Journal of Science 111 (11/12): pp. 1-10.

Rautenbach, V., Coetzee, S., Coltekin, A., 2014. Towards Evaluating the Map Literacy of Planners in 2D Maps and 3D Models in South Africa. In AfricaGEO 2014 Conference Proceedings, pp. 1-12.

Rautenbach, V., Coetzee, S., Coltekin, A., 2016. Development and Evaluation of a Specialized Task Taxonomy for Spatial Planning - A Map Literacy Experiment with Topographic Maps. Under review. 
Rautenbach, V., Coetzee, S., Schiewe, J., Coltekin, A., 2015 b. An Assessment of Visual Variables for the Cartographic Design of 3D Informal Settlement Models. In Proceedings of the 27th International Cartographic Conference. Rio de Janeiro: International Cartographic Association.

Richards, D., Taylor, M., 2015. A Comparison of Learning Gains When Using a 2D Simulation Tool versus a 3D Virtual World: An Experiment to Find the Right Representation Involving the Marginal Value Theorem. Computers \& Education 86: pp. 157-171.

Ross, L., 2010. Virtual 3D City Models in Urban Land Management. Technischen Universität Berlin.

Schroth, O., Pond, E., Campbell, C., Cizek, P., Bohus, S., Sheppard, S., 2011. Tool or Toy? Virtual Globes in Landscape Planning. Future Internet 3 (4): pp. 204-227.

Smallman, H., Cook, M., Cowen, M., 2007. Naïve Realism in Terrain Appreciation. Proceedings of the Human Factors and Ergonomics Society Annual Meeting: pp. 1-6.

van Lammeren, R., Houtkamp, J., Colijn, S., Hilferink, M., Bouwman, A., 2010. Affective Appraisal of 3D Land Use Visualization. Computers, Environment and Urban Systems 34 (6): pp. 465-475.

Wood, M., Pearson, D., Colin, G., Calder, G., Miller, D., Tinto, A., 2005. Comparing the Effects of 2D and 3D Representations on Human Wayfinding. Proceedings of the Symposium 2005 on Location Based Services and Telecartography: pp. 165-170. 